\title{
Intertextualidade: a migração de um conceito
}

\author{
TANia Franco CARvalHaL
}

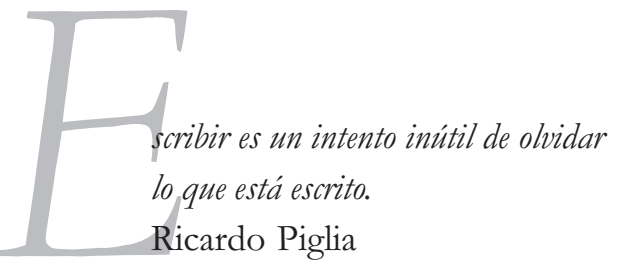

Nos comentários críticos que precedem e fundamentam a leitura de Sarrasine, de Balzac, em S/Z (1971), Roland Barthes observa: le texte unique vaut pour tous les textes de la littérature non en ce qu'il les représente (les abstrail et les égalise), mais en ce que la littérature elle-même n'est jamais qu'un seul texte (BARTHES, 1971: 18-19).

O crítico francês alude, nesta passagem, a uma noção essencial ao comparativismo literário e à reflexão teórica sobre a literatura: a idéia de comunidade textual.

A crença de que há nos textos literários elementos comuns que identificam sua natureza, sem que isso os uniformize, é que ampara a atuação não só da teoria literária como da literatura comparada quando ambas visam à abstração de conceitos a partir da análise textual, orientando-se para aspectos supra-individuais das obras. Assumem, no caso, como finalidade última, a aproximação global da literatura, na qual cabe dar conta da complexidade de relações interliterárias e de como, por força desses processos, se estabelece a tradição. 
Esse procedimento, que afirma a vinculação da literatura comparada com a teoria literária, recupera para os estudos comparativistas a noção de Weltliteratur em novas bases, sem as marcas da inclinação cosmopolita de inícios do século XIX ou da visão utópica de Goethe, quando empregou e difundiu o termo, em 1827. Na perspectiva goethiana, a noção de "literatura mundial" pressupunha a existência de nações com identidade própria e com comunicação no plano literário. A construção lógica do conceito remete à sua origem eurocêntrica, pois deve seu surgimento à pulverização progressiva da língua latina como código universal, que durante séculos constituiu um meio de produção e de comunicação literária na Europa (NAUMANN, 1991). Foi com certeza o aparecimento de várias formas de expressão literária em latim vulgar, transmutado em línguas vulgares, que depois configuraram as diversas literaturas nacionais, o motivo provocador da reflexão sobre relações recíprocas e liames entre elas e além delas. Hoje, sua utópica compreensão do fenômeno há que ser necessariamente revista, a partir de uma concepção de uma perspectiva "planetária”, na qual tem insistido René Etiemble (ETIEMBLE, 1974 [1975], 1982 e 1988).

Mas se Goethe ambicionou a criação de uma literatura mundial para a qual todos os escritores colaborariam, a concepção da literatura como uma totalidade, dinâmica e interativa, perpassa a obra de muitos escritores modernos. Na de Jorge Luís Borges, por exemplo, essa idéia configura-se como uma biblioteca interminável que, ao ser percorrida por um eterno viajante em qualquer direção, comprovaria, no final dos séculos, que os mesmos volumes se repetem em igual desordem.

Na noção do literário como globalidade estão presentes a de "comunidade" e a de "continuidade", sendo esta entendida como um processo que alterna memória e esquecimento. Vigora também aí, de forma subjacente, a perda do conceito de propriedade privada, pois nesse grande conjunto tudo se torna propriedade de todos, patrimônio comum a que os escritores recorrem consciente ou inconscientemente. A tradição se faz por um efeito de memória. Ou como diz Ricardo Piglia: "Para um escritor a memória é a tradição. Uma memória impessoal, feita de citações, na qual se falam todas as línguas. Os fragmentos e os tons de outras escrituras voltam como recordações pessoais. Com mais nitidez, às vezes, que nas recordações vividas" (PIGLIA, 1990). 


\section{II}

É nesse contexto que a noção de intertextualidade se torna muito importante. Sendo um dos princípios básicos da teoria textual, é útil ao comparatista no estudo das relações literárias. Assim, o termo migrou nos estudos literários desde seu emprego por Julia Kristeva, em 1966, para caracterizar a produtividade textual a partir do conceito de dialogismo de M. Bakhtine. No ensaio "Le mot, le dialogue et le roman", a intertextualidade, cunhada e difundida por Kristeva, é explicada como uma propriedade do texto literário, que "se constrói como um mosaico de citações, como absorção e transformação de outro texto". Para ela, "em lugar da noção de intersubjetividade se instala a de intertextualidade e a linguagem poética se lê, ao menos, como dupla". A teoria do texto se fundamenta logo em três grandes premissas: a primeira, "que a linguagem poética é a única infinitude do código", depois, que o texto literário é duplo: "escrita/leitura" e, finalmente, que o texto literário é "um feixe de conexões". Isto posto, temos o texto como "diálogo de várias escrituras", e o que era antes entendido numa relação individual (intersubjetiva) passa a ser coletivizado, ou seja, as relações são estabelecidas no conjunto dos textos. Desse modo, o texto ressalta sua natureza heterotextual, sendo penetrado de alteridade, constituído de outras palavras além das próprias. Por isso, mais tarde, Michel Riffaterre, em La Production du Texte (1979), falará de "indireção semântica", isto é, a obra não significa apenas o que diz. Ela absorve os significados dos textos com os quais dialoga num sentido amplo do termo: o diálogo é aqui estabelecido entre três linguagens, a do escritor, a do destinatário (que pode estar fora ou implícito na obra) e a do contexto cultural, atual ou anterior.

Desse modo, a palavra, que é "dupla", pertence ao texto em questão e a outros, precedentes e diferentes, pertencendo também ao sujeito da escrita e ao destinatário.

Não por acaso Roland Barthes, ainda em $S / Z$, escreveria que "este eu (moi) que se aproxima do texto é já em si mesmo uma pluralidade de outros textos, de códigos infinitos, ou mais exatamente perdidos (cuja origem se perde)" (BARTHES, 1971: 16).

A instrumentalização do conceito teórico foi rápida. Foi tal sua difusão nos anos 1970 que Marc Angenot observou, com razão, que seria possível 
ilustrar a própria noção de intertextualidade com a migração do termo "intertexto" e de seu campo nocional (ANGENOT, 1984).

A idéia varia segundo os contextos teóricos: por vezes integra a poética genética, outras, a estética da recepção; em alguns autores ela ocupa uma posição central; em outros, é termo ocasionalmente empregado. O fato é que a noção fez "fortuna crítica", não surpreendendo, pois, que se transladasse ao domínio comparatista, fortalecendo a solidariedade existente entre as formas de investigação do literário. Desde o número 27 da revista Poétique, "Intertextualités", dirigido por Laurent Jenny, várias publicações são dedicadas ao tema.

A intertextualidade, como propriedade descrita, passou a significar um procedimento indispensável à investigação das relações entre os diversos textos. Tornou-se chave para a leitura e um modo de problematizá-la. Como sinônimo das relações que um texto mantém com um corpus textual pré ou coexistente, a intertextualidade passou a orientar a interpretação, que não pode mais desconhecer os desdobramentos de significados e vai entrelaçálos como a própria origem etimológica da palavra esclarece: texere, isto é, tecer, tramar. Daí "intertexto", que significa "tecer no, misturar tecendo" e, de forma figurada, entrelaçar, reunir, combinar (RUPRECHT, 1984).

O texto permite a leitura de intertextos, ou seja, do "conjunto de textos que se pode aproximar daquele que temos sob os olhos, o conjunto de textos que encontramos na memória de uma dada passagem", como definiu Riffaterre (1979). ${ }^{1}$

É, portanto, na trama do que se perde e do que se recupera, na alternância de esquecimento e memória do que se lê que se organiza a continuidade literária, tal como ela se manifesta em cada texto. A intertextualidade, ao operacionalizar-se, possibilita que se recomponham os fios internos dessa vasta continuidade em seus prolongamentos e rupturas. Mas se a intertextualidade como propriedade textual é seletiva, pois a absorção de elementos alheios responde a uma necessidade particular, o procedimento nos leva a pensar na constituição de uma "tradição" não-ilimitada, como

\footnotetext{
${ }^{1}$ Sobre "intertextualidade" há uma vasta bibliografia teórica. Cabe aqui registrar apenas os números especiais de revistas literárias dedicados à questão. Trata-se de Poétique n. 27 (dirigido por Laurent Jenny), 1976; Sémiotique et Bible, n. 15, 1979; Littérature n. 41, 1981 e Texte, 1984. Veja-se também o livro de Nathalie Piégay-Gros, Introduction à l'intertextualité.
} 
queria T. S. Eliot, mas num conjunto de dimensões formais e temáticas que certos grupos de textos têm em comum.

Nesse contexto, a convenção é importante como elemento que assegura a comunicabilidade, o trânsito do literário. A apropriação significa sempre o conhecimento e domínio das peculiaridades do código. Assim é possível entender como a intertextualidade aponta para a sociabilidade da escrita literária, cuja individualidade se afirma no cruzamento de escritas anteriores.

Já nos distanciamos do sentido restrito com que o termo foi inicialmente empregado e se pode explicitar o conceito como "todas as interações possíveis entre todos os fenômenos culturais". Tomada num sentido largo, a intertextualidade nos permite entender que ler um texto é lançá-lo num espaço interdiscursivo e na relação de vários códigos, que são constituídos pelo "diálogo entre textos e leitura". Por isso a intertextualidade é igualmente entendida como um dado da percepção textual. Já nos Ensaios de estilística estrutural, de 1971, M. Riffaterre encaminhava a reflexão nesse sentido, mostrando que o procedimento intertextual possibilita que se descrevam as convenções interpretativas, dando-nos um verdadeiro "traçado" de leituras.

A contribuição do conceito para os estudos de literatura comparada é visível e essencial, pois modificou as leituras dos modos de apropriação, de absorções e de transformações textuais, alterou o entendimento da "migração" de elementos literários, revertendo as tradicionais noções de "fontes" e "influências". A alteração é substantiva: se a noção de influência tendia a individualizar a obra, sobrepondo o biográfico ao textual e impondo uma causalidade determinista na produção literária, a de intertextualidade, ao designar os sistemas impessoais de interação textual, coletiviza a obra. Por outro lado, se as fontes são, por definição, exteriores ao texto, os traços da existência de intertextos são intratextuais, formadores e constituintes da obra. Se a influência parecia deixar passivo o receptor, minimizando sua importância e privilegiando a noção de originalidade, a compreensão da intertextualidade como propriedade textual elide o sentido negativo e dá ênfase à natureza criativa do processo de produção textual.

Nessa perspectiva, o dado absorvido por um texto é considerado "um formante intertextual", entendido numa relação de "performance" produtora e "competência" receptora do sujeito, seja ele individual ou coletivo. 
Do mesmo modo, se a noção de intertextualidade nos permite incluir as anônimas práticas discursivas da cultura como elementos que permitem a uma obra produzir efeitos de sentido, a noção contribui também para que o comparatista menospreze as "relações de fato" (os tradicionais rapports de faits, que deveriam ser comprovados concretamente) por "relações de valor" (rapports de valeur), cuja comprovação será textual e não histórica.

Graças à reflexão teórica sobre o conceito de intertextualidade, a noção de influência aos moldes tradicionais se tornou inoperante, como também a tese da dependência dela decorrente. Ao investigar as "fontes" na forma convencional, sem atentar para sua funcionalidade na obra que as incorpora ou na literatura a que esta pertence, o comparatismo tradicional deixava de considerar o mais importante, ou seja, como e em que medida a apropriação de uma fonte contribuía para a configuração pessoal daquela obra e para sua inserção no conjunto maior do literário, ao aderir a uma tópica que integra a linguagem convencional, a temática ou os procedimentos técnicos comuns aos escritores.

Em estudo sobre Cláudio Manuel da Costa, difundido graças à organização de Antonio Candido sob o título geral de Capitulos de literatura colonial (1991), Sergio Buarque de Holanda comprova largamente a utilidade dessa leitura renovada de fontes, ao estudar nossa literatura colonial em suas relações com as literaturas das metrópoles, para mostrar, como diz Antonio Candido, "como o tecido da obra literária é uma encruzilhada secular na qual vem bater toda a aventura espiritual do Ocidente" (HOLANDA, 1991: 22). No corpo do ensaio, no qual pela colação direta dos textos explicita como Cláudio se aproxima e se distancia, discrepando do modelo italiano de Pietro Metastasio, Sergio B. de Holanda manifesta com clareza o andamento de sua leitura crítica ao dizer:

"Se aplicada a épocas como a nossa, já saturadas do individualismo romântico, essa determinação dos antepassados espirituais de um autor, tão do gosto dos historiadores positivistas, redunda geralmente numa pesquisa de fontes estéril e inconseqüente; o mesmo não se dirá com relação aos tempos em que a imitação dos grandes modelos do passado se apresentava como virtude e quase como dever. Nesse caso - é o caso, em particular, de Cláudio Manuel da Costa e dos nossos árcades -, a presença de tais modelos pode fornecer-nos, ao contrário, pontos de referência estáveis que serão singularmente úteis para qual- 
quer esforço de inteligência crítica e histórica do mesmo autor" (HOLANDA, 1991: 268-9).

Além de esclarecer quando e por que as pesquisas de fontes se justificam, Sergio Buarque de Holanda se preocupa em comentar as repercussões desse tipo de estudo de forma ampla e diz: "Não são as 'influências' recebidas, através de sua evolução, por um determinado escritor, o que importa verificar num esforço dessa natureza, nem saber as razões particulares que o teriam levado a escolher este ou aquele 'antecedente' literário - pois a verdade é que tais escolhas se prendiam tanto quanto possível, naqueles tempos, a convenções e padrões comumente aceitos e dependiam, em muito menor grau do que hoje, de um critério pessoal -, nem ainda chegar a um julgamento inequívoco de valor. Mas justamente pelo fato de nos apresentar a existência quase obrigatória daqueles 'antecedentes' uma escala de referências mais ou menos fixa, temos maiores probabilidades de, partindo dela, ganhar acesso ao que constitui mais propriamente a parte do autor em sua obra e ao que haja, nesta, de verdadeiramente orgânico e intrínseco". A seguir, ilustra suas afirmações, completando: "Para Cláudio Manuel da Costa, aquele encontro do Metastasio fornece-lhe, numa primeira e inevitável etapa, o modelo ideal que o ajudará a livrar-se, na medida de suas possibilidades, das cadeias que ainda o prendem a uma estética transacta: a do Seiscentismo. A seguir, porém, o mestre antes absorvente irá transformar-se em eficaz estímulo. A esse estímulo deveu o brasileiro a iniciação e o vinco arcádicos que irão marcar toda a sua obra ulterior e sua ação no ambiente natal" (HOLANDA, 1991: 269).

A transcrição dessa passagem do ensaio de Buarque de Holanda evidencia como e em que medida a apropriação de determinados modelos é necessária à constituição de uma certa obra e, por meio dela, alimenta a literatura a que pertence. Evidencia, também, como o jogo intertextual que se estabelece se faz por força de convenções cuja migração nos textos responde pela continuidade literária. E mais, como o ponto de vista comparativo pode esclarecer o intercâmbio literário e suas repercussões na configuração definitiva de cada literatura.

Aliás, foi esse processo de relações interliterárias, objeto central da literatura comparada desde sua concepção, que René Wellek procurou reorientar em seu conhecido ensaio sobre a "Crise da literatura comparada". Já ali dizia: 
"A literatura comparada tem o imenso mérito de combater o falso isolamento das histórias literárias nacionais: está obviamente certa (e tem apresentado um acúmulo de provas para apoiar isso) na sua concepção de uma tradição ocidental coerente de literatura entretecida numa 'rede de inúmeras inter-relações" (WELLEK, p. 244, grifo meu).

Nesta passagem, Wellek pretendia desfazer a dicotomia entre literatura geral e literatura comparada, estabelecida por Van Tieghem, julgando a distinção desnecessária, pois, como disse: "Literatura comparada tornou-se um termo estabelecido para qualquer estudo de literatura que transcenda os limites de uma literatura nacional". Contudo, era preciso ressaltar que esse estudo não poderia deter-se no simples mapeamento de relações entre as diversas literaturas, mas necessitava, sobretudo, explicitar o que essas relações deviam indicar.

Deve-se reconhecer, em René Wellek, una visão sistêmica da literatura e, nessa perspectiva, a "rede de inúmeras inter-relações" de que fala deveria abarcar as relações intertextuais, cuja análise nos ajuda a perceber o andamento dos elementos literários que configuram a tradição, mas também as relações entre as literaturas em sentido amplo, cuja organização em conjuntos supranacionais prefigura o que se poderia entender hoje como literatura mundial.

\section{III}

O alerta de René Wellek, como se sabe, foi produtivo e pode ser lido, hoje, como um impulso às orientações comparativistas que se ocupam com os modos de apropriação literária e permitem entender melhor a constituição e o funcionamento das literaturas bem como suas inter-relações.

Para os estudos dos processos dessas inter-relações têm sido relevantes alguns princípios teóricos estabelecidos e divulgados pelos formalistas russos, particularmente R. Jakobson e Tynianov, pelos estudiosos da escola de Praga, como J. Mukarovsky e F. Vodicka, e por alguns semioticistas russos, como J. Lotman e M. Bakhtine. São básicos os estudos sobre evolução literária e as noções de sistema e de dinamismo funcional. E o que se depreende dos trabalhos de Itamar Even Zohar, da Universidade de Tel Aviv, que, detendo-se especialmente em estudos sobre a literatura hebraica e sobre as 
relações desta com outras literaturas, desenvolveu a noção de polissistema, isto é, da literatura como um sistema heterogêneo, um "sistema de sistemas"; ele explora uma série de hipóteses interdependentes sobre o literário e o comportamento de seus elementos, definindo fenômenos de contato e de interferências entre literaturas.

As investigações de Zohar facilitam o conhecimento do funcionamento interno dos sistemas literários bem como comprovam que esse funcionamento depende de sua articulação com os demais. A aplicação desse tipo de análise se tem revelado rentável sobretudo no esclarecimento de relações que se constituem em fator de evolução literária. Quer dizer, facilitam o entendimento de como e em determinadas situações e em distintos momentos as relações estabelecidas orientam o rumo de uma literatura. E o caso das traduções, pois a atuação da "literatura em tradução" no contexto literário que a acolhe pode determinar sua direção. A noção de polissistema permite o estudo das relações literárias em diversas dimensões, entre sistema canônico e não-canônico, entre literatura tout court e literatura infantil e outras formas ditas populares, evidenciando "tensões" no interior de uma dada literatura, capazes de explicar casos que, por vezes, permanecem enigmáticos. Zohar ilustra-o com uma questão específica da literatura hebraica, que sempre manteve estreitas relações com a literatura russa. São estas relações que explicam por que, em 1880, no chamado revival period, não se encontra na literatura hebraica nenhum sistema não-canônico, pois os elementos nãocanônicos passavam através da literatura russa.

A ampliação e mesmo complementação das propostas de Even Zohar, contidas em Papers for Historical Poetics (1978/1981), que reúne estudos dos anos 1970, pode ser dada pelos estudiosos de Bratislava, liderados por Dionýz Durisin, que desenvolveram a noção de "comunidades interliterárias", visando ao estabelecimento de um sistema teórico e metodológico coerente para as relações literárias. As investigações de Durisin e de seus colaboradores não querem apenas identificar os conjuntos históricos das literaturas e das unidades literárias, históricas e analógicas do passado, como conjuntos supranacionais, mas intentam definir conceitos e categorias que possibilitem interpretar melhor as relações que asseguram sua conformação e continuidade. A constituição dessas comunidades interliterárias é de natureza múltipla, condicionada por fatores variados, que podem ser geográficos políticos, lingüísticos, de proximidade de parentesco ou 
mesmo de analogia de procedimentos artísticos. Além disso, "as comunidades interliterárias não existem nem se desenvolvem isoladamente, mas através de uma interação variável com seu contexto" (DURISIN, 1991). Por isso, cada literatura nacional pode tornar-se, ao longo de seu desenvolvimento histórico, um componente de várias comunidades interliterárias, não se constituindo essas em sistemas fechados ou invariáveis. Essa proposta teórica nos permite reavaliar noções como a da literatura nacional, examinando-a em suas articulações com outras literaturas (CARVALHAL, 1993: 359-68 e 1994: 93-102).

Os estudos mais recentes sobre comunidades interliterárias fogem ao esquematismo e ao determinismo mecânico que ainda pareciam persistir nos primeiros textos. Isto se percebe, por exemplo, no estudo sobre "Retardement, déplacement de phase, développement accéléré”, de István Fried, de Budapeste, no qual há a preocupação em ultrapassar os conceitos fixados de "diferença cronológica" ou de "atraso", dizendo não ser possível reduzir o processo literário ao fator cronológico, pois ele tem cadências próprias. Segundo ele, é preciso aceitar que em algumas literaturas os estilos marcados pela época apareçam incompletos, fragmentários, enquanto em outras se aclimatam e fixam-se correntes diferentes. São vários os fatores que colaboram no processo, sendo impossível condensá-los em construções simplificadas ou esquemáticas e menos ainda apriorísticas. Como dirá: "Nosso trabalho será mais rentável e nós compreenderemos mais exatamente as transformações da literatura no espaço do tempo, se ao longo de nossas reconstruções nós não nos limitarmos a observar et traiter processos reduzidos a um só pólo e esquematizados" (DURISIN, 1987).

Além de possibilitarem a revisão de conceitos, de objetos e de métodos da literatura comparada tradicional, as reflexões sobre comunidades interliterárias permitem que se recupere a perspectiva da literatura mundial sob um novo ângulo. E os estudos de literatura comparada encontram nas questões de intertextualidade e de comunidades interliterárias um campo próprio de investigação no qual se consolida sua articulação com a teoria literária, que lhe fornece o instrumental para fundamentar seus procedimentos, enquanto dá a essa os elementos necessários para que formule conceitos específicos e peculiares aos problemas literários de que o comparativismo se ocupa.

É nesse sentido que a comparação ou confrontação textual, característica da literatura comparada e prática antes ocasional da crítica literária, por meio 
da noção de intertextualidade, passou a ocupar uma posição central nos estudos literários em geral, não apenas comparativistas.

Diante disso, o comparatista se depara com a necessidade de redefinir seus campos de atuação e de acentuar, em sua prática, a compreensão da literatura como um todo. Com o embasamento teórico que recebe por sua aproximação à teoria literária, a literatura comparada tende a acentuar a generalização em detrimento da simples comparação entre elementos e a ampliar os seus domínios numa perspectiva interdiscursiva e interdisciplinar. Investe, portanto, no amplo relacionamento dos textos na cultura. "A possibilidade de comparar a literatura com qualquer coisa", como sugere Jonathan Culler em "Comparative Literature and Literary Theory" (CULLER, 1979), onde refere a comparação do discurso literário com outros tipos de discursos, desde o mais corrente estudo da presença na literatura e nos escritos históricos de esquemas narrativos similares e modelos de compreensão, passando pelos textos autobiográficos até os textos filosóficos e psicanalíticos.

Se a noção de intertextualidade trouxe para a literatura comparada uma revitalização, também lhe provocou um grande desafio: a sua permanente redefinição como prática de leitura que remete constantemente a outros textos, anteriores ou simultâneos, que estão presentes naquele que temos sob os nossos olhos.

\section{Referências Bibliográficas}

ANGENOT, M. Intertextualité, interdiscursivité, discours social. Texte. Paris: Les Editions Trintexte, 1984.

BARTHES, R. S/Z. Paris: Seuil, 1971.

CARVALHAL, T. M. F. O próprio e o alheio: ensaios de literatura comparada. São Leopoldo: Unisinos, 2003. p. 69-87.

. "Comunidades interliterárias e relações entre literaturas de fronteira". In:

ANTELO, Raúl (Org.). Identidade e representação. Florianópolis: UFSC, 1994. . "Diálogo intercultural na América Latina: Machado de Assis e J. L. Borges". In: ADANCZYK, N. (Org.). Dialogo Intercultural: migración de discursos. Varsóvia: CESLA, Universidade de Varsóvia, 1993. 
CULLER, J. "Comparative literature and literary theory". Michigan Germanic Studies, 5, 2. 1979.

DURISIN, D. Les Communautés Interlittéraires spécifiques. Bratislava: Academie des Sciences Slovaque, 1991. . "Sobre las regularidades del proceso interliterario". Revista Casa de las Américas, n. 160, 1987.

ETIEMBLE, R. Ouverture(s) sur un comparatisme planétaire. Paris: C. Bourgois, 1988. - Quelques essais de littérature universelle. Paris: Gallimard, 1982. . Essais de littérature (vraiment) générale. Paris: Gallimard, 1974 [1975].

HOLANDA, S. B. de. Capitulos de literatura colonial. São Paulo: Brasiliense, 1991.

NAUMANN, M. "Entre réalité et utopie: Goethe et sa notion de la Weltliteratur". In: Littérature comparée/Littérature mondiale. Actes du XIème Congrès de la AILC, New York: Peter Lang, 1991.

PIÉGAY-GROS, N. Introduction à l'intertextualité. Paris: Dunod, 1996.

PIGLIA, R. "Memoria y tradición". In: Atas do $2^{\circ}$ Congresso da ABRALIC, Belo Horizonte, 1990.

RIFFATERRE, M. La Production du Texte. Paris: Seuil, 1979.

RUPRECHT, H-G. Intertextualité. Texte. Paris: Les Editions Trintexte, 1984.

WELLEK, R. "Crise da literatura comparada". In: Conceitos de Crítica. São Paulo: Cultrix, s/d. 